\title{
A Danger to the Public? Disposing of Pauper Lunatics in late-Victorian and Edwardian England: Plympton St Mary Union and the Devon County Asylum, 1867-1914
}

\author{
RICHARD ADAIR, BILL FORSYTHE, and JOSEPH MELLING*
}

\section{Introduction}

The introduction and growth of county pauper lunatic asylums during the nineteenth century remains the subject of vigorous debate among social historians of medicine. ${ }^{1}$ There is no question that the proportion of paupers classified as lunatics rose from one in one hundred in 1842 to one in eight by 1910 , though the dynamics underlying this rising trend are only now beginning to be analysed in depth. ${ }^{2}$ It still remains unclear why the rate of certification and committal of people as insane lunatics should have proceeded so much more rapidly than population growth in the Victorian period. This is the question which provides the wider intellectual context for the present essay. In his influential study of the rise of the modern lunatic asylum, Andrew Scull has suggested that the growth of commercialization, industrialization and of new conurbations led to the fragmentation of family relations and compelled more individuals to seek the institutional support of the New Poor Law when the business cycle threw them out of work. Mounting pressure on the workhouse led Guardians and Poor Law officers to seize on the new county asylums (which all counties were required to build after 1845) to dispose of those inmates whose sickness and awkward behaviour posed a threat to the smooth running of the Union. ${ }^{3}$ As a result, the moral treatment of inmates pioneered in the new asylums was quickly

* Dr Richard Adair and Dr Joseph Melling are at the Department of Economic and Social History, and Dr William Forsythe is at the Department of Social Work, University of Exeter, Exeter EX4 4RJ.

We are grateful to Robert Turner for his contributions to the Exminster Project funded by the Wellcome Trust, and to Pamela Michael, University College of Wales at Bangor, for suggesting that we consult the records of the Lunacy Commission at the Public Record Office. We have also benefited from the critical advice of Peter Bartlett, Pamela Michael, Andrew Scull, Akihito Suzuki and David Wright as well as the referees and editors of Medical History. Those faults which remain are our responsibility alone.

\footnotetext{
${ }^{1}$ A T Scull, Museums of madness: the social organization of insanity in nineteenth-century England, London, Allen Lane, 1979; idem, The most
}

solitary of afflictions: madness and society in Britain, 1700-1900, New Haven, Yale University Press, 1993; J K Walton, 'Casting out and bringing back in Victorian England: pauper lunatics, 1840-70', in W Bynum, $R$ Porter and M Shepherd, The anatomy of madness: essays in the history of psychiatry, vol. 2, Institutions and society, London, Tavistock, 1985, pp. 132-46; R Porter, Mind-forg'd manacles: a history of madness in England from the Restoration to the Regency, London, Athlone Press, 1987.

${ }^{2} \mathrm{~K}$ Williams, From pauperism to poverty, London, Routledge and Kegan Paul, 1981, p. 214.

${ }^{3}$ Scull, op. cit., 1993, note 1 above, p. 125 for discussion of significance of struggle over Poor Law and bourgeois rationality which paved the way for the centralization of control, institutional segregation of the insane, differentiation of deviant groups, and emergence of a professional personnel depicted. See also ibid., pp. 10-29. 


\section{Richard Adair, Bill Forsythe, Joseph Melling}

overwhelmed by the arrival of chronic, incurable, and difficult cases from the workhouses. This early deluge forced the "mad doctors" and their staff into a policy of containment and mass control rather than individualized treatment. ${ }^{4}$

Thus for Scull it was the ambitious vision of the new asylum doctors and the declining tolerance of other family members which provide the key elements for the rising tide of admissions between the 1840 s and the 1890 s. The whole argument rests on a premise that the families of the lunatics committed to the county asylums were to be found amongst the poorest segments of society, and also that the divide between pauper and private lunatics reflected the structural division of a class society. ${ }^{5}$ Even if this is true, it remains problematic why so many working-class families should have resorted to the muchloathed workhouse as a means of relief for their family members when they bitterly resented and avoided it as a means of social support in other situations of distress. ${ }^{6}$ Nor is it clear that Scull's general model of structural change and differentiation in nineteenthcentury Britain (drawing as it does on John Walton's migration research) can be sustained for regions such as south-west England. ${ }^{7}$ Such questions need to be addressed in further detailed studies of care and treatment in the Victorian and Edwardian years. In this essay we wish to argue that Scull's interpretation seriously understates the importance and complexity of the Poor Law as an institution which contributed to the mediation and the construction of social relations in these decades.

Impressive local studies have been undertaken in recent years and generally confirm one of Scull's arguments: namely, that the large influx of admissions to the new asylums all but removed the prospect of individual care beyond an initial period of examination and treatment. ${ }^{8}$ There remains the deeper question why and how the numbers sent to the county asylums grew so much more rapidly than either the general population or the clients of the Poor Law in the second half of the nineteenth century. Recent contributions to the social history of lunacy provision have recognized the key role of the Poor Law in the whole process of institutionalization. ${ }^{9}$ Scholars such as Walton, Saunders and Bartlett

\footnotetext{
${ }^{4}$ Ibid., pp. 168-73, 263.

5 Ibid., pp. 354-5: "So that, as the term itself would suggest, pauper lunatics were quite definitely recruited from only the poorer sections of the community." Scull goes on to note that many lunatics must have come from the respectable working class, beyond the ranks of the official pauper class, but "quite plainly, the division between the pauper and the private lunatic reflected accurately the basic class division of Victorian society." We suggest that such a sharp dichotomy of Victorian social classes seems to be a simplification of complex social and cultural identities.

${ }^{6}$ Ibid., pp. 361-3. The key point for Scull is that poorer families lacked the resources to cope more adequately with those pressures which were perceived to cause difficult behaviour. Thus their members were disproportionately represented amongst the insane. This argument only underlines the paradox that a Poor Law system so repugnant to the respectable poor should have been used apparently so widely by those who do not (from our research) appear to have been in desperate circumstances.
}

\footnotetext{
${ }^{7}$ Ibid., pp. 360-2; cf. R Adair, J Melling and $B$ Forsythe, 'Migration, family structure and pauper lunacy in Victorian England: admissions to the Devon County Pauper Lunatic Asylum, 1845-1900', Continuity and Change, 1997, 12 (3).

${ }^{8}$ B Crossley, 'Lunacy in Lancashire: a case study of Prestwich Hospital 1850-1948', MPhil. thesis, Salford University, 1989.

${ }^{9} \mathrm{~F}$ Driver, Power and pauperism: the workhouse system, 1834-1884, Cambridge University Press, 1993; D J Mellett, The prerogative of asylumdom: social, cultural, and administrative aspects of the institutional treatment of the insane in nineteenthcentury Britain, New York, Garland, 1982. We acknowledge that Scull does not devote a large amount of space to the workings of the Old or New Poor Laws, though we suggest that his argument rests on a view of the Poor Law workhouse as a complementary institution to that of the new county asylum. Our purpose is to demonstrate that Scull has underestimated the significance and complexity of Poor Law institutions.
} 


\section{Plympton St Mary Union and the Devon County Asylum, 1867-1914}

have explored the particular ways in which pauper lunatics were handled and deployed through a network of institutions, offering us a close reading of the administrative and legal structures governing the treatment of these individuals. ${ }^{10}$ The present essay seeks to extend these insights into the reciprocal workings of the asylum and the Poor Law by a detailed analysis of the policies and practices which were developed at local level to handle the pauper lunatic. The purpose is not merely to exemplify the complex mechanics of the admission process in one Union but to link different kinds of records and source materials in a way that allows us to track the lunatic's journey to the asylum with a precision which has not previously been achieved. ${ }^{11}$

Our findings demonstrate that the Victorian Poor Law, and more particularly the Union workhouse, was an important filtering stage in the assessment of those who might be identified as pauper lunatics. The institutional grid that we describe at Plympton St Mary depended, in part, on a network of individuals in order to function. The passage of individuals through the institutions studied in this essay clearly shows that the Lunacy legislation (introduced in 1845 and amended in 1862 and 1890) set the framework for local administration, and the 1890 measure appears to have had a local impact which is not always recognized. The practical implementation of these measures was driven by such pressures as Poor Law finance and politics, the preferences of the magistrates, Guardians and Union personnel, as well as a complex pattern of negotiations with families and friends of those potentially or actually identified as pauper lunatics. In an important sense, therefore, the pauper lunatic was "made" by the Poor Law machinery at local level. ${ }^{12}$ The journey to the county asylum depended to a large degree on the relations established between the Guardians of the local Unions and the superintendents of the new institutions. We have indicated elsewhere that significant variations could and did exist in lunacy committals between neighbouring Devon Unions in these decades. ${ }^{13}$ In the following section of the essay we briefly consider the development of the Devon County Pauper Lunatic Asylum and the particular status of the Plympton St Mary Union in this period.

\section{Exminster Asylum and the New Poor Law}

The Devon County Lunatic Asylum was opened at Exminster in 1845 and its population swiftly passed the 400 for whom it was planned; it reached 1400 before 1914 . Under the superintendence of John C Bucknill, Exminster in its early years was an institution which sought to promote good practice and individual treatment and was

\footnotetext{
$10 \mathrm{~J}$ Saunders, 'Institutionalised offenders: a study of the Victorian institution and its inmates with special reference to late nineteenth century Warwickshire', PhD thesis, University of Warwick, 1983; P Bartlett, 'The Poor Law of lunacy: the administration of pauper lunatics in mid-nineteenth century England with special emphasis on Leicestershire and Rutland', $\mathrm{PhD}$ thesis, University College London, 1993.

${ }^{11}$ P Rushton, 'Lunatics and idiots: mental disability, the community, and the Poor Law in north-east England, 1600-1800', Med. Hist., 1988,
}

32: 34-50, provides an illuminating analysis of individuals in transit under the Old Poor Law.

12 The pauper lunatic was, of course, legally constituted by the certification of insanity. It is interesting that the requirement on magistrates to send the lunatic to the asylum was by no means followed through in all cases.

${ }^{13}$ B Forsythe, J Melling and R Adair, 'The New Poor Law and the county pauper lunatic asylum: the Devon experience, 1834-1884', Soc. Hist. Med., 1996, 9: 335-55, p. 336. 
initially regarded approvingly by the Lunacy Commission in London. ${ }^{14}$ Overcrowding pressures were being felt by the late 1850s and, after Bucknill's departure in 1862, the Devon Asylum went into steep decline. Local scandals over corruption and brutality overshadowed its reputation in the late 1860 s and early 1870 s. Control was eventually restored but Exminster appears to have subsided into a routinized and overpopulated institution during the late Victorian period, subjected to periodic criticism from the Commissioners and undertaking only limited medical research. These resource problems could be perceived in distinctive ways by the different Devon Unions, with important consequences for the relief of pauper lunatics in the early decades of the Asylum's life. ${ }^{15}$

Thus we can locate the relations between the Plympton St Mary Union and the Exminster Asylum in the rise and fall of moral treatment between the early heroic years of Bucknill and the strains which started to emerge between 1857 and 1862. These tensions continued during the tenure of George Saunders, who remained as Superintendent until 1898 . The 1862 statutory provisions enabled local Unions again to house some lunatics within the walls of a specialized ward at the workhouse and may have been an early recognition that the hopes of curability raised in the 1840s had certainly not been realized for a significant section of the asylum inmates. The Devon Unions continued to pursue very different policies in respect of their pauper lunatics and resorted to a variety of institutions and practices according to the Guardians' perceptions of local circumstances and needs. Our evidence also casts some doubt on the underlying assumption that a disproportionate number of the insane came from the poorest sections of the community. ${ }^{16}$ It is debatable whether most of the Devonians who entered the County Asylum would have come into contact with the Union workhouse had they not been regarded by family, friends and neighbours as insane. It certainly appears that the resources not only of the individual concerned but also of the family network to which he or she belonged were significant factors in determining entry to the new asylums and length of stay there, as Walton has argued. ${ }^{17}$

The Plympton St Mary Union is relatively unusual in providing us with the source materials to examine the interplay of these forces and determine the conditions under which individuals were most likely to be sent to the county asylum. We will show that the range of people who came into contact with the Poor Law was remarkably wide but that certain criteria for dispatch to Exminster do emerge from these documents.

\footnotetext{
${ }^{14} \mathrm{D}$ J Mellett, 'Bureaucracy and mental illness: the Commissioners in Lunacy 1845-90', Med. Hist., 1981, 25: 221-50, p. 228, reveals the rift between Bucknill and the Lunacy Commission in 1857 over the appointment of non-specialist medical Commissioners. This was compounded soon after by a dispute between the Exminster Superintendent and the Commission, documented in the Lunacy Commission Minutes: Public Record Office [hereafter PRO] Lunacy Commission series MH50, 17.6.1857, 23.9.1857, 9.6.1858.
}

\footnotetext{
${ }^{15}$ Forsythe, et. al., op. cit., note 13 above, pp. 342-6.

16 Cf. A Scull, Social order/mental disorder, London, Routledge, 1989, p. 245: "A wide range of nineteenth-century observers commented on how much laxer the standards were for judging a poor person to be insane, and how much readier both local poor-law authorities and lower-class families were to commit decrepit and troublesome people to the asylum".

${ }^{17}$ Walton, op. cit., note 1 above, pp. 140-1.
} 


\section{The Plympton St Mary Union}

In this section we can do no more than briefly sketch some of the main features of one Devon area. Plympton St Mary (hereafter Plympton) was a compact Union bordering Plymouth, the largest city in Devon, which gradually extended into the Plympton boundaries and converted part of Plympton into a suburban area of the city by the outbreak of war in 1914. Even at this date the Plympton Union retained many of its original agrarian features and possessed a population which had migrated in from surrounding countryside areas, as well as out from the city, as employment declined in Devon's central agricultural districts after the 1870s. The Union comprised the parishes of Plymstock, Compton Gifford and Egg Buckland bordering the city, as well as rural settlements such as Wembury, Newton Ferrers and Ermington. In these years the Union had a clear preponderance of women over men (a ratio of 1.1 to 1 in 1871 and 1891), in common with most parts of Devon. The occupational profile of the area was also more agrarian and less industrialized than the county as a whole, possessing a high number of females in domestic service. As we would expect from a district bordering the expanding metropolis of Plymouth, there was much movement in and out of the city as well as across the county border of Cornwall. Evidence from Asylum registers also suggests that there was a remarkably low level of geographical mobility amongst those who were to be the future inmates of Exminster. More than half the male admissions were resident in their parish of birth when arriving at the Devon Asylum, which compares with less than 39 per cent for a sample group of non-patients in the area. This pattern of low migration and long residence in parishes appears to conform with a more general pattern for the county. Although there are clearly many difficulties in attempting to select a representative area for the whole county, we would argue that Plympton possesses many of the key features (including suburbanization, rural migration, employment change and compact Union administration) which are discussed in the secondary literature dealing with the impact of demographic and social change on asylum admissions in the Victorian age. ${ }^{18}$ Our claim is therefore that Plympton can be seen as fairly representative of Devon as a whole and that the county can be usefully compared with an area such as Lancashire in these decades.

Plympton's Guardians also appear to have reflected the social composition of the propertied classes in this area of Devon, bordering as it did a major commercial and naval town. In 1884-85 they comprised thirty-eight elected members and thirty-two ex officio members, the latter dominating the major offices including the chairmanship. These $e x$ officio members had a distinct military presence along with a reverend, a baronet, two Lords and twenty-two esquires. The elected members had a more agricultural and mercantile flavour, with sixteen "yeomen", as well as ten farmers, three gentlemen, and a smattering of agents, businessmen, manufacturers and small traders. There was relatively little change in the social composition of the Guardians in the period we are considering. Whilst such notables comprised the leading Guardians of the Poor, the day to day administration of the Poor Law itself fell on the shoulders of the relieving officers and medical officers employed by the Union.

\footnotetext{
18 Adair, et al., op. cit., note 7 above, provides further discussion of migration patterns.
} 


\section{Bristol Channel}

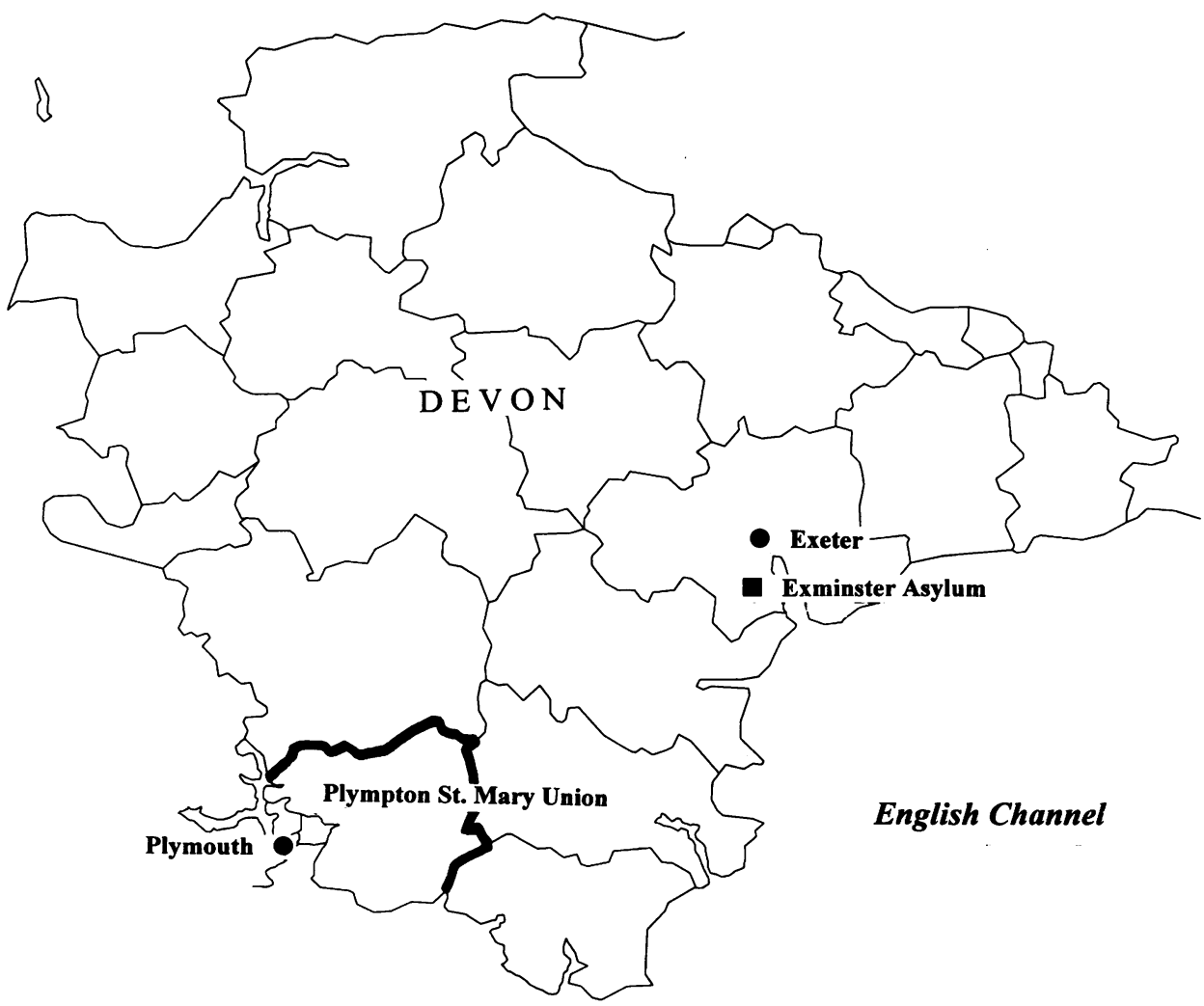

The Devon Poor Law Unions, 1845-1914, indicating the position of Plympton St Mary Union in relation to the Devon County Lunatic Asylum at Exminster.

The pattern here was one of remarkable consistency. In the period 1867-1914, eight relieving officers signed ninety certificates of admission to the Devon County Asylum. ${ }^{19}$ Eighty of these were in the hand of just three men: Henry Scoble Pearce (1870-85), James Scott (1886-1908) and H Feldermann (1909-14). We can find a similar pattern with the medical officers as twelve doctors signed ninety certificates, though seventy-nine were authorized by three physicians: Richard Ellery undertook forty-six examinations between 1870 and 1899, C H G Prance fifteen between 1900 and 1908, and W D Stamp eighteen between 1908 and 1914. The remarkable continuities and consistencies in the posts of relieving officers and medical officers in this period help to explain the smooth functioning of the system until the turn of the century. Much has been written about the standards of asylum care and the medical celebrities who dominated public debates on the

\footnotetext{
19 The sample numbers for various analyses of this population may seem to jump around alarmingly: this is usually because the information available for
}

each individual is lacking in some respects and therefore many persons can be used in only some of the analyses. 
care of the insane, but it is clear that the fate of the pauper lunatic was initially (and critically) decided by these obscure individuals working within the framework of the New Poor Law.

The great majority of Victorian lunatics were found amongst the lower orders of society and were legally defined as "pauper lunatics", or clients of the 1834 Poor Law. The basic principle of this law was that claimants for public relief should be willing to face a test of their genuine need for assistance, which was originally conceived in terms of compulsory admission to the Union workhouse for all applicants. ${ }^{20} \mathrm{On}$ admission to the workhouse, the pauper would undergo medical examination by the medical officer, and anyone found to be diseased in mind or body was to be placed in the infirmary. The strict letter of the law provided that those found to be (dangerous) lunatics could be detained at the workhouse for only fourteen days before being dispatched to an asylum, though legislation of 1862 permitted the Unions to retain harmless and chronic lunatics within the workhouse. In practice, it would appear that Plympton workhouse (in common with a great many other Unions) retained a significant number of pauper lunatics within its own premises and sent only those whom it considered dangerous or difficult to the County Asylum at Exminster. The legislation of 1890 tightened up the certification procedures considerably and, although designed to avoid the casual dispatch of lunatics, the provisions may paradoxically have assisted the flow of people from the workhouse as local physicians became more concerned about the strict requirements of diagnosis and treatment. $^{21}$

It is here that the roles of the relieving officer and the medical officer of the Union become critical to an understanding of pauper lunacy. Within the workhouse there is no doubt that the master, the matron and the workhouse medical officer were the key figures. These would be accountable to the relieving officer of the Union who was in turn answerable to the Guardians for the proper administration of poor relief. Within Plympton, individual districts were the responsibility of a district medical officer appointed to treat sick paupers referred by the relieving officer, including those suspected of insanity. ${ }^{22}$ The provisions for care appeared deceptively simple: before the $1890 \mathrm{Act}$, a committal order to the county asylum could be signed either by an individual magistrate or by a relieving officer and a clergyman, supported by a certificate of lunacy completed by a recognized physician, surgeon or apothecary. ${ }^{23}$ After 1890 the situation was tightened so that a committal order could be signed only by a magistrate and had to be accompanied by a certificate of lunacy signed by two physicians.

Before and after the 1890 legislation, the relieving officer of the Union played a critical role in the process of institutionalizing the pauper lunatic, as Peter Bartlett has pointed

\footnotetext{
${ }^{20}$ For a variety of reasons the strict principles of 1834 , as is well known, were modified in practice even in the rural districts. See A Digby, Pauper palaces, London, Routledge and Kegan Paul, 1978, for discussion mainly of East Anglia.

21 There was certainly a large influx of admissions to the Exminster Asylum in the 1890s, at a time when recovery rates were rising and death rates (after 1900) were to rise noticeably.

22 If the lunatic remained in the community itself
}

then an individual could of course reach Exminster by a different route.

${ }^{23}$ Up to 1853 the doctor was not to be a Poor Law medical officer but after that date he almost invariably was. For the "hybrid agglomeration" of the "medical profession" in early Victorian England see M J Peterson, The medical profession in midVictorian London, Berkeley, University of California Press, 1978, p. 38. 


\section{Richard Adair, Bill Forsythe, Joseph Melling}

out. ${ }^{24}$ Not only did the relieving officer decide whether an individual should be referred to the district medical officer, but he also made the original application to the magistrate and was responsible for conveying the certified lunatic to the county asylum. It is equally clear that the workhouse itself was a vital clearing house for the identification and disposal of pauper lunatics in the later Victorian era. The original 1834 Poor Law stipulation on the removal of dangerous lunatics within fourteen days appears to have been widely interpreted by Guardians so as to retain numerous individuals in workhouses (rather than asylums). The statutory right of detention awaited the passage of the 1867 Poor Law Amendment Act. ${ }^{25}$ In this procedure the workhouse's medical officer also played a key role. $^{26}$

We can now see the significance of the long reign of a small and compact group of individuals at the Plympton St Mary Union in this period. The diagnoses and commentaries found in the Poor Law accounts, certificates of lunacy, committal orders and admission registers of the Exminster Asylum itself provide an illuminating insight into the machinery by which an individual was identified, labelled and dispatched as a pauper lunatic in Victorian England. These documents were often constructed in a surprising fashion: opinions not merely of other physicians but of nurses and attendants found their way into the statements recorded on the admission of a patient to the County Asylum. ${ }^{27}$ The origins of many of these testaments probably lay in the interviews which the workhouse medical officer held with interested parties, including family members, though he undoubtedly edited and selected comments which confirmed his own impressions.

This was the context for admissions and departures from the workhouse in these years, where those identified as lunatics formed one section within the larger pauper host at Plympton St Mary. ${ }^{28}$ In the Poor Law records, the admissions for the census years 1871 , 1881 and 1891 appear as shown in Table 1. Before we can disinter the pauper lunatic from the broader mass of the inmates arriving at the workhouse, it is important to note that many of the labels attached to the incomers were general rather than precise. The generic term "destitution" covered the vast majority of admissions, never less than two-thirds and up to four-fifths of cases. Illness, covering acute and chronic conditions, was also a significant category, as was pregnancy and those actually born in the workhouse. Lunatics were a very small group, only one "supposed lunatic" in 1871, one "insane" in 1881, and two "supposed lunatic" and one "supposed to be insane" in 1891. Some of those Plympton inmates who eventually found their way to Exminster were originally admitted suffering

\footnotetext{
24 Bartlett, op. cit., note 10 above, pp. 140-1.

25 Ibid., pp. 63-4 note 69.

${ }^{26}$ For the complexity of the role of the workhouse medical officer as "sanitarian, surgeon, psychiatrist, midwife and disciplinarian as well as physician" see M A Crowther, The workhouse system, 1834-1929, Athens, Georgia, University of Georgia Press, 1981, p. 164 .

${ }^{27}$ In one case we find the opinion of a policeman who brought Samuel L. to Exminster, that he "had Brain Fever" soberly noted in the certificate. Devon Record Office (hereafter DRO), Devon County Lunatic Asylum Admission Certificate (hereafter
}

EAC), 1870 January 18 . Case: $3769 \mathrm{~A} / \mathrm{H} 2 / 26$. These bundles form part of the major Exe Vale deposit at the Devon Record Office, Exeter. In order to avoid embarrassment to living relatives we have suppressed the full names of all individuals who appear in the records. They are usually indicated by first name and initial.

${ }^{28}$ Article 19 of the General Order for Accounts issued by the Poor Law Board in January 1867 specified that records of admissions and discharges should be recorded, though very few of these documents have actually survived. 
Plympton St Mary Union and the Devon County Asylum, 1867-1914

Table 1

Reasons for entering Plympton Workhouse, 1871-1891

\begin{tabular}{lrrr}
\hline & 1871 & 1881 & 1891 \\
\hline Destitution & 195 & 93 & 97 \\
Illness & 20 & 14 & 9 \\
Born in workhouse & 17 & 6 & 7 \\
Pregnancy & 12 & 5 & 4 \\
Lunatic & 1 & 1 & 3 \\
Removal & & 2 & \\
Until sent to indust. school & & 1 & \\
Returned from eye infirmary & & 1 & 9 \\
Old age & 2 & 2 & 129 \\
Deserted by parents & 247 & 143 & \\
[Not given] & & 3 & \\
\hline $\mathrm{N}$ & & & \\
\hline
\end{tabular}

from illness or destitution, presumably (in some instances) because their insanity was not fully apparent until they had been resident at the workhouse for a period.

This conclusion is supported by the explanations provided for those leaving the workhouse in this period. Not only are the reasons much more varied, they also indicate the capacity of individuals and their families to arrange for their removal from the workhouse. The sample years yield the results shown in Table 2. Again there is a substantial majority of three- to four-fifths of the inmates leaving the Plympton workhouse at their own request or at that of members of their family, some of whom were also resident in the Union institution at this time. Again we get an impression of the relatively tiny presence of identified lunatics amongst the pauper host with only eight out of the 510 discharges being dispatched directly to Exminster and fourteen going to other institutions. Only a trickle of paupers moved in and out of the workhouse from (or to) another lunatic or idiots' institution.

It is tempting to assume that the rationale behind the disposal of the pauper lunatic was exclusively financial and that considerations of cost weighed most heavily with the Guardians and their officials. This assumption obscures the process by which fiscal rationality was itself constructed. Our research confirms the growing impression that the introduction and administration of the New Poor Law can be read as an extension of aristocratic and traditional values as much as the triumph of Benthamite reasoning. ${ }^{29}$ The communities which comprised the Plympton St Mary Union were certainly not prosperous by the standards of some areas of England and by the 1880s the Guardians were anxious to ensure that the burden of maintaining pauper lunatics did not fall too heavily on the ratepayers of these parishes, and therefore family members were expected to contribute to the cost of asylum care and removal between institutions.

\footnotetext{
${ }^{29}$ Forsythe, et al., op. cit., note 13 above, pp. 335-8 and passim.
} 
Richard Adair, Bill Forsythe, Joseph Melling

Table 2

Reasons for leaving Plympton Workhouse, 1871-1891

\begin{tabular}{lrrr}
\hline & 1871 & 1881 & 1891 \\
\hline Own request & 182 & 50 & 74 \\
Left for service & 13 & 10 & 2 \\
Absconded & 12 & 6 & 6 \\
Dead & 13 & 15 & 20 \\
Sent to the asylum & 2 & 3 & 2 \\
Order of removal & 5 & 3 & 1 \\
To eye infirmary & 4 & 29 & \\
Sent to hospital & 1 & 1 & 1 \\
Request of mother & 3 & 4 & 12 \\
Request of father & 1 & 1 & 1 \\
Request of brother & 2 & 1 & 1 \\
Request of friends & & 3 & 140 \\
Order of Magistrate & & 2 & \\
Police custody & & 132 & \\
Sent to training ship & 238 & & \\
\hline N & & & \\
\hline
\end{tabular}

When we consider the different roads to the asylum for the pauper lunatic, we need to recall that the Guardians were responsible both for the general conduct of the Union (including the workhouse) and for the dispatch of lunatics to the place of treatment. Thus the Plympton Guardians were in correspondence with the relatives of individuals transported to Exminster from places as remote as Portsmouth Borough Asylum, seeking, in this particular case, to recover the costs of the journey from the father. ${ }^{30}$ On another occasion the Guardians were prepared to remove an inmate of the County Asylum to the charge of the private mad house keepers at Plympton House, apparently for financial reasons. ${ }^{31}$ The discrimination in the institutions used for different cases in the later nineteenth century (one female was kept at the private Fisherton House whilst another was removed to the Exminster Asylum) suggests that a range of financial, family and pathological circumstances were taken into consideration when the care was decided at the Board of Guardians. ${ }^{32}$ It has to be said that the Guardians were dealing with a complex array of personal cases, including idiots who were lodged in and removed from the Western Counties Idiots' Asylum at Starcross (a few miles from Exminster). Assessments were made in these institutions as well as at the workhouse. ${ }^{33}$

Yet a salient feature of the workhouse clients stands out in this regard: no paupers placed at the private institutions (such as Plympton House or Fisherton House) or in other borough asylums (such as Portsmouth) had any connection with the workhouse and, with hardly any exceptions, the Union workhouse had contact with the County Asylum at

\footnotetext{
${ }^{30}$ West Devon Record Office (hereafter WDRO), Plympton St Mary, Guardian Minute Book, (hereafter GMB), WDRO 1576/10, 9 June 1882.
}

\footnotetext{
31 GMB, 1 February 1884.

32 GMB, 24 October 1884.

33 GMB, 9 April 1886, 26 April 1886.
} 
Exminster only. ${ }^{34}$ Lunatics entering the Plympton workhouse had three options: to remain within the confines of the workhouse, to return to the community had which sent them, or to journey up to Exminster. This may indicate an important principle in the administration of lunacy in these decades: namely, that only a certain number of those being handled as "pauper lunatics" under the 1845 legislation were perceived as coming within the terms of the 1834 New Poor Law. In other words, only a proportion of the lunatics for whom the Guardians were responsible would have been seen as the destitute groups for whom the 1834 legislation was classically designed. Here lies a fundamental conundrum of the administration of pauper lunacy which has rarely been acknowledged in the existing literature: those identified as pauper lunatics frequently belonged to social groups who were far removed from that section of the population recognized as typical clients of the workhouse or even the familiar claimants on the Poor Law. This basic contradiction within the legislative provision for lunacy may help to explain the varied provision made for the insane in areas such as Plympton.

This hypothesis is given some support by the structure of the sources themselves. Of the 101 pauper lunatics who went to Exminster between 1867 and 1914 from Plympton St Mary workhouse, only 36 were entered as having that institution as their previous place of abode in the Exminster admission registers. This suggests not merely that it is hazardous to rely on such sources as a guide to the numbers of Asylum inmates passing through workhouses en route to Exminster, but also that those compiling the records did not perceive these admissions as workhouse residents. Not surprisingly, it was the more temporary inmates who were least likely to be mentioned. More detailed analysis of 93 individuals for the whole period 1867-1914 has revealed that 58 of this group (62 per cent) had no other contact with the workhouse apart from their entry prior to being sent on to Exminster. Another 29 individuals ( 31 per cent of the group) experienced up to three sets of entrances and exits before or after their committal, but only 6 ( 7 per cent) were in and out of the workhouse four times or more before entry en route to the Devon County Asylum. Since five of the six with the greatest number of entries came to Exminster before 1895 , it was largely a phenomenon of the earlier years of our study. The data as a whole show that for the large and increasing majority of patients progressing through Plympton to Exminster, their only contact with the workhouse was immediately preceding their committal.

The overall distribution over time of patients moving from Plympton workhouse to Exminster shows a steady flow from 1867 to 1900 , with 17 to 20 in each decade, followed after 1900 by a sharp upturn in admissions to the Asylum around 1905. We might conclude that the Plympton workhouse was increasingly used as a transit point for travellers to Exminster, with future patients remaining at the Union only long enough to be examined and processed. The evidence shows that this was not in fact the case. If we break the period at 1905 , we find that 42 per cent of pre-1905 admissions stayed in the workhouse no longer than a fortnight while this fell to 37 per cent of future Asylum admissions in the years 1905-1914. When we examine the period as a whole, it appears

\footnotetext{
34 There were two Starcross (i.e. Western Counties Idiots' Asylum) patients who came from the workhouse but these appear to have been the only exceptions. See J Melling, R Adair and B Forsythe,
}

\footnotetext{
"“A proper lunatic for two years": pauper lunatic children in Victorian and Edwardian England. Child admissions to the Devon County Asylum, 1845-1914', J. soc. Hist., 1997, 30 (4): 371-405.
} 


\section{Richard Adair, Bill Forsythe, Joseph Melling}

that about two-fifths remained less than a fortnight and a third resided at the workhouse more than a fortnight and up to a year, with a quarter remaining for more than a year. So we can see that the largest group of future Exminster inmates coming from the workhouse were transferred quickly and only a limited proportion of future residents at the Devon County Lunatic Asylum had been at the Union premises for more than a year. This would counter claims frequently made that the Guardians of such Unions sent only the chronic and incurable cases from the workhouse to the asylums, thereby reducing the cure rates recorded in these institutions. It also lends weight to the view that the very short-term residents of the union houses were not seen as workhouse paupers in the classical sense. The next section examines the characteristics of the pauper lunatics resident in the Plympton workhouse in more depth.

\section{The Workhouse Lunatics: Characteristics}

The scanty nature of the sources permits only an oblique insight into the circumstances and characteristics of most of the individuals who came to the lunatic ward of the Plympton workhouse, though we occasionally receive vivid flashes of personal tragedy which illuminate the desperate situation in which many local people struggled, and the scope for personal initiative which existed in other cases. From the materials surveyed, the key importance of family bonds and institutional capacities emerges in the collective biography of those who were identified as insane in these decades. Of the 98 Exminster patients from Plympton for whom we have information, 55 were males and 43 females, though the preponderance of men in the numbers going to the Asylum is a phenomenon of the years after 1890 rather than of the whole period. The age distribution of these people was heavily concentrated in the 21 to 50 age group for both sexes, which conforms with the Exminster population as a whole. ${ }^{35}$ More than half the future patients had no previous record of treatment for insanity elsewhere and a mere 13 per cent had been to the Devon Asylum previously, though some patients had been inmates of other institutions in neighbouring counties or distant places such as Essex. A significant gender difference is also apparent in the rate of dispatch to the Asylum. Men were usually transferred quickly, whereas most of the very long-term workhouse pauper lunatics were women. Yet it was females who were more likely to be discharged as recovered, though proportions were low for both groups with 36 per cent of women recovering as against 21 per cent of men. Almost two-thirds of Plympton workhouse clients died at Exminster, a significantly higher proportion than that of the Asylum entrants as a whole at a little above two-fifths. This suggests that pauper lunatics dispatched from the workhouse had substantially less hope of cure than those not associated with the workhouse. Even though men were sent more rapidly to the Devon County Asylum they were more likely to become chronic patients and to die there.

The family backgrounds of the future Exminster inmates is also interesting. Of the 91 individuals for whom information is available, only a fifth ( 21 per cent) did not have an identifiable relative in the local area, with almost two-thirds (63 per cent) having a parent,

\footnotetext{
${ }^{35}$ No one under eighteen went to Exminster from Plympton workhouse and only a moderate number of elderly people.
} 
spouse, sibling or child living within a reasonable distance. Very few cases indeed (14 per cent) were entered as having no settled parish of residence, which indicates that a large majority of the Exminster entrants were part of stable family networks rather than members of a transient vagrant host within Devon society. A picture slowly emerges from such statistics of a section of the population which was unable to call on their families to extricate them from the workhouse and therefore became liable to transportation to the Asylum under particular conditions. In the next section we consider what were the circumstances under which such a transfer became likely or inevitable.

\section{The Road to the Asylum: Institutional Shunting in Action}

The conditions under which an inmate of the Plympton workhouse would be transferred to Exminster were more complex than may be assumed from such general surveys as that provided by Andrew Scull. The criterion used most commonly as a basis for removal from the workhouse appears to have been that of "dangerousness". There was, in fact, a legal requirement that the dangerous lunatic had to be removed to an asylum within fourteen days of entry, though in practice it was left to Poor Law officials to determine the level of danger presented by an individual. The 1862 provisions which allowed Guardians to retain chronic and incurable lunatics in their premises also recognized the possibility that such inmates would be difficult to manage, and after 1900 a padded cell seems to have been added to the Plympton workhouse. In earlier times there had been dangerous characters such as James F. who, having stabbed two or three men at his lodgings, stayed at the workhouse in transit from Bodmin Asylum to Exminster in 1874, and never left the County Asylum until his death almost fifty years later. ${ }^{36}$

Apart from such cases of spectacular violence, the incidence and assessment of dangerousness becomes much less certain and appears to have been the result of individual and subjective judgments rather than any objective analysis. There is only a small difference, for example, in the number of days spent in the workhouse before transfer to the Asylum between those individuals categorized as "dangerous" at entry to Exminster and those not. It is likely that that many non-dangerous patients were sent on very quickly and also that some individuals who were later classified as dangerous (such as some epileptics) were not recognized as such on entry to the Asylum. ${ }^{37}$ It is significant that almost half (43 of 88) were defined as dangerous on entry to Exminster from Plympton workhouse, with little variation in the distribution between genders or over time. The circumstances of dangerousness appear to have been defined as much in relation to the person in authority as to other inmates, as when an inmate struck staff of the workhouse and threatened other occupants with knives and plates, "so that they are in constant fear". 38

\footnotetext{
36 West Devon Record Office, Workhouse Admission and Discharges Book (hereafter WADB), 31 March 1874. Exminster admission certificate, 1874, WDRO H2/30a, 1 April 1874. Workhouse admissions and discharge books for the Plympton Union between 1867-1916 are referenced WDRO 1576/84-95.

${ }^{37}$ EAC, 1886, H2/42, 31 July 1886 , for the case of Henry B., who was described as having been an
}

epileptic for many years "but lately the Fits have been increasing sometimes having as many as six a day, which leaves him in a very violent state."

${ }^{38}$ EAC 1871, H2/27, 13 November 1871; 1903, H2/59d, 23 November 1903; 1905, H2/61a, 29

March 1905; 1895, H2/51d, 19 October 1895; 1897 , H2/53d, 18 October 1897. 


\section{Richard Adair, Bill Forsythe, Joseph Melling}

In the 1870s there appears to have been a surprising level of tolerance towards some forms of aggressive and disobedient behaviour, possibly because the Exminster Asylum was rapidly filling beyond capacity and its staff were anxious not to encourage admissions from workhouses. Edward L. was depicted by the Plympton medical officer as having in the past six years "frequently threatened the lives of other inmates of the workhouse", keeping them "in a continued state of fear". The Master added that "he scales the walls \& runs away, returning in a state of unconsciousness through drink". This ended when $L$. was committed to the Asylum as part of a general clear-out of awkward inmates. Twentyone years later he was discharged from Exminster "not improved", his eventual fate being unknown. ${ }^{39}$ The conditions under which an individual could be defined as dangerous varied widely and, in some instances at least, the label of dangerousness seems to have been a pretext for the rapid removal of the person concerned after a period of tolerance. William M. was sent to Exminster in 1870, nearly blind and with general paralysis, after having many times threatened to kill "the man in charge of the room where he sleeps", who was likely to have been another workhouse inmate. ${ }^{40}$ The Plympton authorities similarly accepted Martha H.'s repeated attacks of mania for over three years and her habit of "singing all sorts of nonsense", including replies to any questions put to her, but she went too far by jumping from a window and found herself on the road to Exminster. ${ }^{41}$

In other circumstances much less remarkable behaviour seems to have provoked an early dispatch of the offending individual to the County Asylum. Although some very elderly patients were described as dangerous, it is hard to avoid the conclusion that they were merely disruptive to the perceived good order of the workhouse. Thus Susan G. was sent off to Exminster at the age of eighty-eight after being typecast as very violent and dangerous but it appears that the real substance of the decision was her habit of "continually quarrelling and talking incoherently using bad \& obscene language". 42 Whether the prospective patients were anxious to leave the workhouse or the authorities to dispose of them, a number of individuals who were credited with extravagant acts of violence against attendants or plots to blow up the building were not found to be threatening personalities when installed at the County Asylum. ${ }^{43}$

Such variations in description and characterization should not obscure the fact that particular kinds of behaviour were consistently unacceptable at the workhouse and seen as a basis for early dispatch to the Asylum. Three forms of bad behaviour were never tolerated for long: incendiarism, attempted suicide, and outrageous immorality. In addition to these failings, any inmate who displayed dirty physical habits was liable to qualify for a passage to Exminster. When Henry W. showed an unnerving habit of getting out of bed at three in the morning and lighting a fire, he qualified for a place at the County Asylum. ${ }^{44}$

Similarly, Emma S.'s threats to commit suicide were taken seriously when in 1899 she informed the workhouse staff that she was about to "destroy the Gas fittings to Cause an

${ }^{39}$ EAC, 1873, H2/29, 1 September 1873.

40 EAC, 1870, H2/26, 28 November 1870.

${ }^{41}$ EAC, 1872, H2/28, 13 July 1872.

${ }^{42}$ EAC, 1873, H2/29, 1 September 1873.

${ }^{43}$ EAC, 1907, H2/63a, 28 February 1907; 1899, H2/55c, 29 September 1899. M. may have resided temporarily in a private mad-house since the medical certificate was signed by Dr Langworthy, presumably of the famous Plympton House dynasty, who ordered his removal to the Plympton Workhouse "under guard".

${ }^{44}$ EAC, 1880, H2/36b, 27 November 1880. 
Explosion", a threat which brought her quickly to Exminster. ${ }^{45}$ Here again the Asylum staff found her not to be dangerous, which may be a tribute to her tenacity in wanting to get away from the workhouse rather than to the sagacity of the authorities.

The prospect of a suicidal inmate was one which the Plympton Guardians and officials took very seriously on most occasions, perhaps as much because of the resources involved in the careful supervision and treatment of such people as from concern at the scandal of a workhouse death. Among the entrants from Plympton classified as suicidal on entry to Exminster, the average time spent in the workhouse was only a quarter of that of the nonsuicidal admissions (162 compared to 650 days). ${ }^{46}$ The actual numbers of Plympton workhouse entrants who were so identified when coming to the Asylum was fairly limited ( 15 of 88 or 17 per cent), with the ratio falling noticeably after 1890 from 22 per cent to 14 per cent of admissions. Once again there is a significant variation between the genders of reported suicidal intentions with one in 3.5 females classed as suicidal compared with one in 12.5 males. As with the incidence of violence in the Plympton workhouse, the alleged threat of suicide could be seized on by the authorities as a trigger for dispatch to the Devon Asylum. So when the elderly Mary D., who had delusions of a pension from the Queen, "took off her garters \& tied them together \& said she would strangle herself", she was sent away. ${ }^{47}$ By way of contrast, Jane D. was held for months after she first tried to cut her throat, and only after an elaborate suicide attempt by hanging was she finally sent on the same journey. ${ }^{48}$ This tardiness in removal appears to have been rare, with inmates despatched whenever suicide was seriously threatened, even shortly after childbirth. The decision appears to have been taken that suicidal inmates could not be effectively housed at the workhouse.

Even where patients were not thought to be actively seeking to do violence to others or themselves, the fact that their behaviour could pose a threat to health and order was sometimes sufficient for their committal to the Asylum. William Henry E. was quite blind and insisted on wandering about "in dangerous places". 49 Various inmates would bang their head against doors, place their hands in the chimney fire, and so forth. ${ }^{50} \mathrm{~A}$ particular problem for the Union authorities was the predicament of seriously incapable idiot children and imbeciles of all ages. For they were not welcomed at Starcross where a capacity for education or training was required, and the Exminster physicians recognized, even in the earliest days, that the County Asylum could provide no specialist care or hope of cure. Thus, Alice C., a teenage inmate, was described on her arrival at the County Asylum as "perfectly lost to all reason", constantly "picking out the cinders from the fire grate, and placing them in her bosom", but she had proved too difficult to be looked after in the workhouse. ${ }^{51}$

Other and older individuals were perceived as more culpable in their conduct and inclinations. Outrageous behaviour inside and even outside the walls of the workhouse

\footnotetext{
${ }^{45}$ EAC, 1899, H2/55c, 29 September 1899.

46 The median length of workhouse stay for patients classified as suicidal on their subsequent admission to Exminster was 23 days, as compared with 33.5 days for those clearly classified as nonsuicidal. Of this latter group, slightly less than twothirds $(64 \%)$ remained less than six months in the workhouse. This compares with more than four-fifths
}

(82\%) of the "suicidal" patients who were dispatched to the Devon Asylum within that time.

${ }^{47}$ EAC, 1872, H2/28, 16 October 1872.

${ }^{48}$ EAC, 1888, H2/44, 11 August 1888.

49 EAC, 1909, H2/65d, 2 December 1909.

50 EAC, 1870, H2/26, 22 October 1870; and 1874, H2/30b, 5 December 1874 for Elizabeth A.

${ }^{51}$ EAC, 1877, H2/33, 12 January 1877. 


\section{Richard Adair, Bill Forsythe, Joseph Melling}

were among the grounds for the dispatch of the offending lunatic to the County institution. What is interesting is that the behaviour that caused most offence was often that which disrupted the good order and harmony of the workhouse, rather than the manifestations of serious derangement on the part of the perpetrator. Mischief rather than mental confusion was a term found in the descriptions provided in the certificates of the relevant medical officers at Plympton. Thus Eliza $\mathrm{H}$. was portrayed as "destructive to bedding, very idle \& quarrelsome, . . . restless \& full of mischief[,] being insensible to persuasion \& kindness". ${ }^{52}$ Before casually dismissing this testimony from the Matron of the workhouse (and wife of its Master), we should recall that workhouses might possess as much claim to moral treatment in the decades of chronic overcrowding and rising eugenicist sentiments as asylums such as Exminster. Even so, good order was paramount and noisiness was not tolerated. Elizabeth B.'s inappropriate singing proved fatal to her prospects of continued residence when it was coupled with night-time ravings. ${ }^{53}$ Indeed, good behaviour at night was more important than during the day, and any tendency to walk about at night or get into the beds of other inmates was not tolerated for long. The use of opiates sometimes preceded the decision to transfer to Exminster, but the acid test was quietness in the hours of sleep and the degree of mischievous intent imputed to the individual. ${ }^{54}$

Running around naked was also a fast lane to Exminster, particularly if the individual was recalcitrant in other respects. Refusal to work (Charles George J.), or rejecting workhouse clothes (Fanny W.), or inclinations to leave the workhouse Infirmary without his clothes (Archibald H.), all qualified as reasons for dispatch. ${ }^{55}$ In numerous other cases the epithet employed to justify the transportation of the Plympton pauper to the County institution was that of "dirty habits", which appeared to stretch from a blunt description of physical incontinence to an implication of indecent conduct; nor does there seem to have been growing tolerance of such lapses over time. Albert George $\mathrm{H}$. was sent up from Plympton in 1904 with otherwise trivial symptoms of insanity, such as a vacant expression, but with the telling phrase added that he had been "dirty in personal habits during detention". 56 Similarly, Robert McQ. was said to be lately much more noisy, difficult to manage and refusing to stay in bed at night, but the fact that he was also "very dirty in his habits" probably tipped the scales against his remaining at Plympton. ${ }^{57}$

This theme of appropriate behaviour offers an important thread connecting the world of the workhouse with wider society, and the agencies of the Poor Law with those of public order in Victorian England. The reported facts of the original detention of the pauper lunatic also cast light on the importance of family and kinship networks in the individual's journey through the system of social administration in this period. The local police often played a key role in bringing estranged persons to the attention of the Union authorities, particularly if they were found wandering abroad without proper care and control. Females appear to have been perceived as particularly vulnerable and subject to arrest in

52 EAC, 1883, H2/39, 10 August 1883.

${ }^{53}$ EAC, 1874, H2/30a, 26 March 1874. Her details noted that she had "always appeared half an idiot".

${ }^{54}$ EAC, 1871, H2/27, 18 March 1871, for the case of William T. who was blind on admission to Exminster, where he died within weeks, and was reported to have been "searching for things with mischievous intent".

55 EAC, 1900, H2/56d, 21 December 1900; 1879, H2/35a, 5 April 1879; 1912, H2/68d, 23 October 1912.

${ }^{56}$ EAC, 1904, H2/60d, 21 November 1904.

${ }^{57}$ EAC, 1909, H2/65c, 20 July 1909. 
this situation. Eliza O. was brought to the Plympton workhouse in 1881 by a policeman "who found her wandering about alone in a wood \& had been for a week subsisting on blackberries \& unable to give any account of herself". ${ }^{58}$ Men seem to have had to display rather more outrageous conduct to qualify for detention, as when Frederick P. arrived at the Union establishment two years earlier, having developed the habit of entering private houses and undressing himself. ${ }^{59}$ Outraging public sensibilities was again important when Frederick Charles $\mathrm{H}$. was turned over to the police and thence to the workhouse after he made a nuisance of himself at church, disturbing the congregation. ${ }^{60}$ William S. took a more rustic route. He was delivered to the Union authorities in 1895 after having slept in a barn and on being ordered away by the farmer, was found a few minutes later "quite naked bathing in the Horse Pond". 61

Even if such individuals fell victim to a general sweep of vagrants and tinkers in the district, it is evident that they formed a small minority of the total pauper throng who ended up at Exminster. We can see that the criteria used by the Guardians, relieving officer and medical officers of the Union were heavily coloured by the perceptions of officials not only within the workhouse but in the police and prison forces also. Notions of good order and orderly conduct seem to have figured as prominently as attempts at medical diagnoses in the characterization of the individual's behaviour. What we now need to consider is whether the pauper lunatic was caught completely in the jaws of an administrative system which gave no scope for choice or if there was room for manoeuvre within the interstices of the Poor Law that inmates and their families could exploit in ways that gave them some degree of control over their own fate as prospective patients of the County Asylum.

\section{The Workhouse Regime: The Experience of Asylum Institutionalization}

It is always tempting to portray the Victorian and Edwardian lunatic asylum system as a complex bureaucratic maze, built by the celebrated "mad doctors" and reformers of the nineteenth century, in which the inmates lost all control of their own destiny. The impressive analyses of insanity in the nineteenth century offered by scholars such as Andrew Scull and Elaine Showalter tend to strengthen the impression that the women and men who entered the new asylums were people in crisis, deposited in these institutions on the authority of male physicians and subjected to the control of professionals who employed a highly class-biased and gendered mode of treatment. ${ }^{62}$ What we still lack is detailed evidence to test such claims and in particular a close reading of the primary sources which would throw light on the mechanics of institutional care in the period we are examining. Our evidence suggests that we may need a more subtle understanding of

\footnotetext{
${ }^{58}$ EAC, 1881, H2/37b, 23 August 1881. This woman had seemingly evaded registration in Devon at the census earlier that year. She may of course have been living outside the county, but it is equally likely that she had slipped through the net via vagrancy or homelessness.

59 EAC, 1879, H2/35a, 19 May 1879.

${ }^{60}$ EAC, 1905, H2/61c, 19 August 1905.

${ }^{61}$ EAC, 1895, H2/51b, 20 July 1895.
}

\footnotetext{
62 It is fair to note that both Scull and Showalter emphasize the impact of diminishing family tolerance of difficult members on the rate of admissions to the county asylums, implying scope for variations in tolerance. See also D Wright, 'Getting out of the asylum: understanding the confinement of the insane in the nineteenth century', Soc. Hist. Med., 1997, 10 (1): 137-55, for a recent appraisal.
} 


\section{Richard Adair, Bill Forsythe, Joseph Melling}

the strategies which individuals and their families devised to utilize the asylum system, as well as a recognition of the repertoire of options which the medical profession followed in handling the Victorian lunatic. In particular, we follow Walton in emphasizing that the county asylum proved to be only one possible means of disposing of the pauper lunatic and that a significant number of people were treated within the Plympton workhouse itself. Many other potential clients of the Devon County Asylum were simply removed from the workhouse at the request of their families and friends. This again suggests the limits to the power and inclination of the medical profession to incarcerate even those clearly distressed.

There certainly is evidence that a number of people became institutionalized at Plympton, in the sense that, once identified as returnees to workhouse or community from Exminster, they became more eligible for dispatch to the Asylum as soon as they reappeared in the workhouse. An individual recognized as an old Exminster hand was much more readily returned to the Asylum almost regardless of the symptoms displayed. Maria J. was quickly sent on to the care of Dr Saunders in 1884, though the rationale was simply that "she is continually talking of all sorts of unreasonable things, is very excited, and last night searching the floor for an imaginary sovereign she said she had lost". 63 Similarly, John M. had been in Exminster five times previously when he was sent there again in 1905, though his only symptom of insanity was that he "sits absolutely silent and shows no sign of intelligence". ${ }^{64}$ When Mary Bate $\mathrm{H}$. arrived at the workhouse pregnant in 1905, having suffered from mental strain in her previous delivery, she was sent up to Exminster before displaying any remarkable symptoms. ${ }^{65}$ These people seem to have been typecast as Exminster candidates and alternated between Asylum, workhouse and community according to personal circumstances that are usually obscure.

There are also important examples of women and men who struggled to avoid the journey to the Asylum and to keep their families together in desperate circumstances. We can chart the descent into madness and specialist care of the heads of families and the tragic progress to the Asylum via numerous visits to the workhouse. Elizabeth A. had probably visited Plympton workhouse several times before she first appears in the records in February 1868 as a deserted wife of thirty-six. She brought her five children with her: William (b. 1858), Richard (b. 1861), Caroline (b. 1862), Thomas (b. 1864) and Robert (b. 1867). In a few weeks she discharged herself only to return with her destitute young family a few days later. A further bid for independence in May lasted only a day and by late July her eldest son, William (aged eleven), had left at his own request. She followed with the four remaining children. This marked the beginning of the disintegration of the family, with Richard, Caroline and Thomas re-admitted in a state of destitution on 3 November, without their mother. Elizabeth maintained herself with her youngest in the outside world until 6 December 1869, when destitution again forced her and Robert back inside. In June 1870, Elizabeth took her four children and a fifth, George (perhaps born in the workhouse), out again but survived only until supper time. In the early autumn the invisible husband intervened and requested the discharge of Richard, Caroline and Thomas. His wife followed a few days after with Robert and George, only to return a day later.

${ }^{63}$ EAC, 1884, H2/40, 3 July 1884.

${ }^{65}$ EAC, 1905, H2/61c, 31 August 1905.

${ }^{64}$ EAC, 1905, H2/61a, 26 January 1905. 


\section{Plympton St Mary Union and the Devon County Asylum, 1867-1914}

Ever determined, Elizabeth discharged herself and the children on 18 October, reappeared six days later and stayed until February 1871, when she left for four days. And so it went on: four day absences from the workhouse every few months until August 1871 when she departed with her two youngest children and remained out until March 1873 when she was returned by the request of Dr Govett who described her as suffering from "illness and destitution". She brought with her a baby, Elizabeth Ann (b. 1872), as well as her two youngest children. Never one to linger, Elizabeth discharged herself and her children on 7 April and lasted until December when she returned suffering from "illness". Robert and George followed in a few days. By then their mother had left for Exminster, never to return. After two days in the workhouse, Dr Ellery had examined Elizabeth and found her "continually calling out names of imaginary people, appears very excited, \& when spoken to answers in a loud tone of voice \& says she is very very bad and is sure she will never be better". The workhouse nurse testified that Elizabeth had tried to get up the chimney and place her hands in the fire. The diagnosis given was dementia, though the duration of the attack was thought to be only about a week. She was to remain in Exminster for more than twenty years before dying there in 1894, aged about sixty-three.

The bleak tragedy of Elizabeth A. and her family vividly illustrates the personal dilemmas which lie behind the statistics of destitution and insanity in this period. The important point seems to be that Elizabeth was apparently unable to call on an extended family support outside the workhouse. She seems to have had a sister living in Pomphlete, the same area of Plymstock as she herself came from, and was still married on entry to Exminster but the whereabouts of her husband and eldest children are not given. ${ }^{66}$ It appears that the workhouse was ready to receive Mrs A. and her children as soon as they applied. Her deteriorating health may have been the result of the strain of struggling to escape from the workhouse and to maintain herself in the outside world. Committal to the Asylum was suddenly decided upon when she appeared alone and ill at the gates of the Union in the winter of 1873 . The capacity of the workhouse as a place of treatment for pauper lunatics is discussed below.

In contrast to the tragic case of the A. family, some patients appear to have pursued their own agenda for treatment within the system. The evidence from our study indicates that at least a number of individuals were clearly anxious to be removed from the workhouse to the Asylum, assuming that better conditions awaited them at Exminster. Pauper lunatics occasionally made statements which appear to have been designed to achieve this outcome, as when John R. told the Plympton workhouse medical officer in September 1870 that "altho[ugh] he is a little better this morning in a short time he may be so bad as to Require four men to hold him", threatening to cut his own throat. ${ }^{67}$ Charlotte C. was regularly in and out of Exminster and informed the workhouse medical officer in 1880 by letter that "she is determined to kill herself, and will eat nothing so as to starve herself to death". After striking herself on the head with a poker and thrusting pins and needles into her arm, the Poor Law authorities were persuaded and she was removed to the Asylum. ${ }^{68}$ Eliza H. not only intimidated those around her with her threats on their lives as she moved between workhouse and Asylum in the $1880 \mathrm{~s}$, but triumphantly declared that "she can not be hanged as she is a lunatic". ${ }^{69}$ This secured her passage to Exminster once more.

66 Certificate of Elizabeth A., No. 4708, H2/30b.

${ }^{67}$ EAC, 1870, H2/26, 9 September 1870.
${ }^{68}$ EAC, 1880, H2/36a, 8 March 1880.

${ }^{69}$ EAC, 1883, H2/39, 10 August 1883. 


\section{Richard Adair, Bill Forsythe, Joseph Melling}

There were also a number of cases in which patients identified as idiots or imbeciles were shuttled between Plympton, Exminster and the Western Counties Idiots' Asylum at Starcross in an arbitrary way. A major consideration was the sheer physical resources expended on persons such as Rhoda S., of whom it was noted that "two persons at least are required to dress her[,] one to forcibly hold her[,] the other to put on the clothes". ${ }^{70}$ Where such idiots or imbeciles could be usefully employed on menial tasks around the workhouse kitchen and quarters, they could be retained, though in awkward cases the institution found difficulty in coping with the needs of the individual concerned. It seems clear that the pre-war asylum system largely failed to recognize the demands of such severely disabled people and they drifted between institutions according to the pressures of the moment. The next section considers the function of the Plympton workhouse as a clearing house for those individuals who were returned from the Asylum to the Union and as a place of treatment for potential inmates of Exminster who were never sent there and who remained at Plympton. We know very little about either of these two situations and the following discussion merely introduces the subject for exploration.

\section{The Workhouse Regime: A Case for Treatment? Destinations and Effectiveness of Institutional Care}

Throughout the Victorian era there was considerable debate as to the suitability of keeping lunatics in the care of the workhouse and even of receiving them back after discharge from Exminster. Medical celebrities such as Bucknill were bitterly opposed to the retention of lunatics in these premises and even to their return to Poor Law accommodation after treatment at an asylum such as Exminster. Historians have been more sceptical of the claims made by such heroic professionals, and even contemporary Guardians were wary of the promises of cure offered by these asylum physicians after the disappointments of the 1850s and 1860s. This section seeks to provide a limited assessment of the effectiveness of care offered by the Union and its impact on the destination of those who did not receive treatment at the specialist hands of the Asylum doctors.

Numerous individuals who entered Plympton workhouse were described in terms ranging from "supposed insane" and "wandering lunatic" to "mentally weak", "feebleminded" and "eccentric". Many of these never continued their journey to Exminster. Some were returned quickly to the community but others remained in the Union premises for a significant period. What is remarkable is that they can almost all be traced to the later years of our study, after the passing of the 1890 Lunacy legislation. Among 55 individuals who belong to this group of non-Asylum lunatics, only two date from before 1890 . Between 1891 and 1898, 27 such personalities entered Plympton workhouse, and were followed by 25 others between 1899 and 1914. This may reflect more rigorous and detailed recording of cases in the 1890 s, when terms such as "simple-minded" and "deranged" appear for the first time, as well as more formal procedures being met for the diagnosis of insane individuals. In any case, the Poor Law appears to have been functioning as a more effective diagnostic filter for the classification of the insane and weak-minded from 1890 onwards.

${ }^{70}$ EAC, 1906, H2/62b, 29 June 1906. 


\section{Plympton St Mary Union and the Devon County Asylum, 1867-1914}

Yet it is in the handling of these cases that we can also see various informal arrangements and family ties playing an effective role in the late Victorian and Edwardian years. A comparison of the length of stay and eventual fate of 47 non-Asylum lunatics reveals that more than half ( 57.5 per cent) left the workhouse within a month, including three who died and one transferred to Plymouth workhouse. The remaining 23 were discharged at their own or their families' request. These included James M. J., admitted in 1890 and discharged at his own request within four days on the agreement of the medical officer, and Dot Rose C. of Egg Buckland, who arrived "feeble-minded" in 1911 and was promptly taken out again by her married sister two days later. ${ }^{71}$ The presence or absence of a family member appears to have been an important consideration, particularly perhaps for females. Elsie A., a twenty-year-old clerk from Prince Rock, was brought to the workhouse in 1906, having been found by a coastguardsman near Fort Borsand at 1.00 a.m. wearing only a nightdress, having abandoned her clothes at the cliffs a mile away. Despite her desperate condition, she was released from the workhouse a week later to the care of her mother with the "consent of doctor \& magistrate". ${ }^{72}$ Where the family or friends of even wandering lunatics appeared to claim them, their request for custody appears to have been almost invariably granted with the specific approval of the medical officer. Thus the most common experience of those identified as insane who did not reach the Asylum was for them to return again to their own communities and family or friends within a brief period of arriving at the workhouse.

If a workhouse inmate identified as a candidate for infirmary or lunacy ward care was not quickly returned to family or friends, the prospect for early release was much less promising. Nine non-asylum individuals remained in Plympton workhouse for periods between a month and a year, and four of these were eventually released at their own request or to family or friends. They included sad cases such as "weak-minded" Mary Ann P. of Ivybridge, who was brought by her mother without an order and, after giving birth in the workhouse two days later, remained there until her baby died and was then promptly taken out again by her mother. ${ }^{73}$ Another inmate of the workhouse Infirmary, Theodore S., had been ordered there by magistrates in 1912 after attempting to cut his throat, and remained as a model patient until discharging himself in May $1913 .{ }^{74}$ In contrast to such dischargees, two other inmates died in the workhouse and three (presumably idiotic) younger people were transferred to Starcross, Devonport Union, and the Crownhill Children's Home at Plymouth. Eleven others remained on Plympton premises for longer than a year, four of them dying there. A majority (seven) of even these long-stay inmates of the workhouse eventually went home at their own request, or that of their family and friends. One such was Emma G., who had lived at the workhouse as a "quiet and willing" inmate for almost three years when she was taken away by friends in August 1898. ${ }^{75}$

There seems little doubt that the workhouse Infirmary continued to function not merely as an alternative to Exminster for hopeless and chronic cases in the late Victorian and Edwardian years but apparently as an effective form of asylum which aided recovery for a limited number of individuals. The same institution also served as a place of residence for natives of Plympton returning to their home area from the Devon Asylum. In all, there

\footnotetext{
71 WADB, 3 October 1893, 7 October 1893; 22 February 1911, 24 February 1911.

72 WADB, 12 April 1906, 19 April 1906.
}

\footnotetext{
73 WADB, 28 January 1903, 8 June 1903.

74 WADB, 22 July 1912, 16 May 1913.

75 WADB, 13 November 1895, 24 August 1898.
} 


\section{Richard Adair, Bill Forsythe, Joseph Melling}

were twenty-two occasions between 1867 and 1914 when the workhouse admitted paupers directly from Exminster. The first half of the period, up to 1890, saw seven such events while the second half saw fifteen, with a burst around 1908-9. This may be broadly indicative of a closer tie-in of the various institutions dealing with pauper lunacy over time. These returnees divide almost exactly into two groups; eleven who were moved on to the community or elsewhere within a month, and eleven who remained at the workhouse for more than a year. Five of these longer-stay inmates went back to Exminster, most between 1904 and $1914 .^{76}$ The pattern seems to have been that the longer-term residents of the workhouse who had come back from the Asylum would stay for many years, with only two returning to their own community. The prospects for the short-stay returnees was much brighter. Of the eleven who left the workhouse within a month of return, one (William R.) absconded on the first day in $1869 .{ }^{77}$ Most were taken out by members of their family or at their own request. ${ }^{78}$ Others were discharged by the Guardians or relieving officer and only one was returned to Exminster. ${ }^{79}$ This suggests that about half of those who were discharged back to the workhouse had fair prospects of returning to their families and communities, and the workhouse may have functioned as a place where a trial assessment of the discharged lunatic could be made.

The overall pattern of workhouse care at Plympton St Mary can be detected from the biographical details we have provided thus far. The small number of transfers from the workhouse to institutions other than the County Asylum always occurred within a couple of months of the individual coming to Plympton Union, most of the arrivals actually being returned quickly to their own community. It appears that the relieving officer or his colleagues instigated a search for close family or friends of the person concerned. Only if the family refused to take the "pauper lunatic", or if the inmate resisted the return to the community, would he or she settle down and often end up at Exminster. If no family or friend appeared to claim the lunatic and if the symptoms of insanity caused no great disruption of the workhouse regime, there was a tendency to retain the individual on the assumption that their condition might justify discharge. John P. was picked up as a wandering lunatic in 1898 and was reported as merely having "delusions as to possession of fabulous wealth, and says he has done impossible things". ${ }^{80} \mathrm{He}$ remained at Plympton for a year before being sent to Exminster. John M. lived on dreamy fantasies of marrying the Queen's daughter and loading ships with money to be sent to New York to distribute amongst the poor, before being dispatched to the Asylum. ${ }^{81}$ The key point seems to have been to retain such individuals for a period to see if family or friends claimed them, and if after that time they proved neither useful to the Union nor capable of being given their liberty, the asylum option then came into view. By the 1890s the Guardians were reluctant to see such individuals remaining inside the workhouse if they had little prospect of removal.

Our evidence also indicates that a paradoxical consequence of the 1890 legislation was to encourage a more elaborate examination and verification of workhouse inmates. Facilities were also extended so that such examinations could take place. This enabled the

\footnotetext{
76 WADB, 13 July 1872,22 July 1872.

77 WADB, 9 October 1869.

78 WADB, 21 December 1911; 4 January 1909; 13 October 1903; 14 April 1892; 8 May 1911.
} 
Union to hold difficult cases and gave scope for their release from custody without dispatch to the Asylum. Noah P., a labourer of Plympton St Maurice, arrived on a threeday detention order in November 1904 and was immediately placed in the padded room for two examinations by Dr Prance (medical officer). Prance eventually concluded that he could "find no trace of mental affliction which would authorize his being removed to Exminster Asylum", and P. was released two days later to his wife. ${ }^{82} \mathrm{He}$ returned the following year under another three-day order and remained for ten days before leaving at his own request, with the physician's permission. ${ }^{83}$ In these cases we may also be registering the break up of the close nexus between relieving officers and medical officers in the Union as the old stagers-Pearce, Scott and Ellery-retired, and the new guard adopted different views on the mental condition of the entrants. In September 1908 a disagreement arose when the new medical officer, Dr Stamp, admitted a labourer, Thomas K. On the previous day the Magistrate, Crews, had examined K. "with a view to having a summary reception order for Exminster Asylum signed", but this was rejected by Dr Stamp and K. discharged himself four days later and never returned to the workhouse. ${ }^{84}$ There may have been a new assertiveness amongst the Poor Law medical officers which had been absent in the earlier generations, but we also see unexpected frictions emerge in the Edwardian years that were almost unknown earlier.

\section{Conclusions}

This essay is designed as a contribution to the growing literature in the social history of insanity which emphasizes the important role of the Poor Law in the administration of Victorian lunacy legislation. ${ }^{85}$ The seminal studies of lunatic asylums by Scull noted the importance of the workhouse in the stigmatization of the pauper lunatic as well as the growing inclination of working-class families to resort to state asylums to dispose of their awkward and unproductive relatives. Walton stressed the impact of suicidal behaviour and the strength of family bonds in determining the dispatch of individuals to county asylums in the mid-Victorian years. Saunders raised the question whether the asylum functioned as a place of "last rather than first resort", where kinship ties and the location of relatives were key factors shaping the destiny of the putative lunatic. ${ }^{86}$ Our evidence supports the view that the Poor Law and its local medical officers played a critical, and neglected, role in the identification and treatment of the insane during the nineteenth century. The records of the Plympton St Mary Union also suggest that the presence of family members and their representations to Poor Law officials were often the decisive influence in the dispatch to Exminster, retention in the workhouse, or the retrieval to the family residence. Many of the families who presented their relatives at the Plympton workhouse appear to have been struggling for some time with stressful behaviour and, as we have seen, when faced with the prospect of the individuals being sent to Exminster they decided to take them home. ${ }^{87}$ Where a person lacked family support, or where this was uncertain, he or she was vulnerable not only to the difficulties of destitution but also to certification and dispatch

82 WADB, 7 November 1904, 9 November 1904.

83 WADB, 16 December 1905, 26 December 1905.

${ }^{84}$ WADB, 22 September 1908, 26 September
${ }^{85}$ Bartlett, op. cit., note 10 above.

${ }^{86}$ Saunders, op. cit., note 10 above, p. 313.

87 Walton, op. cit., note 1 above, pp. 140-1. 


\section{Richard Adair, Bill Forsythe, Joseph Melling}

to the Asylum. The tragic case of Elizabeth A. suggests the circumstances in which a lone mother could descend into insanity after many years of intermittent workhouse habitation. The figures on long-stay versus short-stay residents of Plympton's workhouse also indicates that those without relatives were more likely to be institutionalized and when they were eventually sent to the Asylum they were less likely to return.

We can say with some confidence that the construction of the Victorian lunatic was the work of many hands and the outcome of a series of institutional decisions. The Poor Law was at the centre of this process. Not only was the Plympton workhouse used as a transit point for many who journeyed to Exminster from the Union, but it also functioned as an alternative locus of treatment and detention for those who were identified as pauper lunatics. These included those individuals who were sent to the County Asylum after a period of time, those who were en route back to their communities from the Asylum, and those who were never to enter the gates of the Devon Asylum in their lives. The forces which pushed people towards or away from Exminster were channeled along various institutional grooves. The workhouse at Plympton appears to have been pursuing its own priorities in filtering inmates towards a variety of destinations in this period. Where the pauper began to threaten the good order of the workhouse and when there was no realistic prospect of accommodation with family or friends, the person was usually dispatched without delay. For the Victorian workhouse master, lunatics were merely a small and disruptive sub-category, who tied up resources by being challenging, destructive, and insensible to the usual discipline and penalties of the establishment. Workhouse masters needed to secure the co-operation of the relieving officer and more especially the workhouse medical officer, though the continuities in the careers of these post-holders at Plympton appear to have ensured a collaborative relationship which was sustained for most of the period.

One of the factors which may have transformed this stable arrangement at the Devon Union was the passing of the 1890 Lunacy Act. In Plympton's case, this legislation emerges as a watershed in the development of lunacy treatment at local level. Greater rigour was required in the examination and classification of suspected lunatics, and the extended vocabulary of medical terms being used appears to have had greatest impact on that group of people covered by the generic phrase "idiot or imbecile" before 1890 . Until that year the criteria for deciding if a lunatic went to Exminster appear to have been the propensity to violence (against self or others), usefulness, or disruptiveness within the workhouse. This brings us to an important point. The legal requirement on the Poor Law authorities (recognized from 1845) to remove any "dangerous lunatic" to the asylum was the subject of varying interpretations. The generic term "dangerous" would be employed as readily as the epithet "dirty" as a rationale for the speedy removal of the offensive inmate to another place. As we have seen, these terms were loose and subjective rather than specific or consistent and usually reflected the scale of tolerance of the workhouse staff and fellow occupants rather than a sober medical diagnosis. The legislation of 1890 appears to have encouraged the elaboration of terms to describe the insane and those of unsound mind but the use of this lexicon of madness continued to depend on the actors involved and their evaluation of the situation. After 1890, both magistrates and physicians were compelled to be more precise in their reasoning for committal and there was a perceptible decline in the close relationships between officers and medical men 


\section{Plympton St Mary Union and the Devon County Asylum, 1867-1914}

characteristic of the earlier decades. Our evidence also reveals a strong pattern of family consultation in the later years. When relatives or friends appeared, even deeply distressed individuals were often released to them on request. Other factors which may have affected such decisions were the availability of space at the Asylum and the pressures on space at the workhouse itself.

The records of Plympton St Mary Union throw a little light on the broader social forces which were engaged in the administration of pauper lunacy in nineteenth-century England. We have argued that there was a fundamental tension implicit in the legislation of 1845 which required anyone dispatched to the county asylum to be first certified as both a pauper and a lunatic. The literature on the growth of admissions to lunatic asylums in the nineteenth century has not completely resolved the question why so many families were ready to see their members stigmatized as clients of the Poor Law and as mad. The assumption that the lunatics were drawn from the most marginalized and physically mobile social groups is not supported by our evidence. The social background of those identified as lunatics was extremely varied. Exminster's intake from this Union included journalists, blacksmiths, clerks and labourers as well as the elderly, teenage idiots, pregnant women, and alcoholics. Vagrants, wanderers and those without connections in the district formed only a small proportion of the total sent to Plympton as suspected lunatics: for a majority of those who went to Exminster the Union workhouse was no more than an administrative channel to the County Asylum. We have also seen how few of those entering the workhouse were registered as pauper lunatics on their arrival.

Such findings must weaken the assertion that those entering the Victorian asylum were invariably gathered from the poorest sections of society and from the most desperate families, still less were they destitute people institutionalized in the workhouse. The evidence also raises the possibility that the administration of pauper lunacy did not imply a simple or consistent process of stigmatization. The shame incurred by contact with the Poor Law cannot be discounted. Whilst there were some families who were willing to see their relatives reside in the workhouse, many could contemplate only their passage to Exminster as quickly as possible. Even so, the pattern of dispatch suggests an important degree of negotiation and close contact with Poor Law officials throughout the period. It may therefore be useful to understand the certification of madness in the nineteenth century as the application of legal, medical and institutional terminology to situations where non-asylum arrangements had failed and where the costs of containment were too great for those who could restrain or care for the prospective lunatic. Those who came to the Asylum were in need not so much of material resources as of personal and institutional support. Further exploration of the problem of resources and needs must wait for more research into the occupational, class and family background of those who sought out the Poor Law as the place where lunacy itself might be verified. 